Published in final edited form as:

Am J Hematol. 2017 August ; 92(8): 780-788. doi:10.1002/ajh.24770.

\title{
Feasibility Trial for Primary Stroke Prevention in Children with Sickle Cell Anemia in Nigeria (SPIN Trial)
}

\author{
Najibah Galadanci, MBBS, MPH ${ }^{\star}$, Shehu Umar Abdullahi, MBBS, FWACPaed ${ }^{1,{ }^{*}}$, Leah D. \\ Vance ${ }^{2,{ }^{*}}$, Abdulkadir Musa Tabari, MBBS, FMCR, FICS $^{5}$, Shehi Ali, MBBS, FWACS ${ }^{3}$, \\ Raymond Belonwu, MBBS, FWACPaed ${ }^{3}$, Auwal Salihu, MBBS, FMCPsych ${ }^{2}$, Aisha Amal \\ Galadanci, MBBS ${ }^{4}$, Binta Wudil Jibir, MBBS, MTroped, FWACP ${ }^{1}$, Halima Bello-Manga, \\ MBBS, MPH, FMCPath ${ }^{6}$, Kathleen Neville, MD, MS, MBA, FAAP, FCCP7 , Fenella J. Kirkham, \\ MD, FRCP, FRCPCH ${ }^{8}$, Yu Shyr, PhD $^{9}$, Sharon Phillips, MSPH ${ }^{10}$, Brittany V. Covert, MPH ${ }^{10}$, \\ Adetola A. Kassim, MD, MS ${ }^{11}$, Lori C. Jordan, MD, PhD ${ }^{12}$, Muktar H. Aliyu, MBBS, MPH, \\ DrPH $^{11}$, and Michael R. DeBaun, MD, MPH ${ }^{13,11}$ \\ ${ }^{1}$ Departments of Hematology and Blood Transfusion, Bayero University/Aminu Kano Teaching \\ Hospital, Kano, Nigeria \\ ${ }^{2}$ Pediatrics, Bayero University/Aminu Kano Teaching Hospital, Kano, Nigeria \\ ${ }^{3}$ Radiology, Bayero University/Aminu Kano Teaching Hospital, Kano, Nigeria \\ ${ }^{4}$ Psychiatry, Bayero University/Aminu Kano Teaching Hospital, Kano, Nigeria \\ ${ }^{5}$ Doris Duke Clinical Research Mentorship Program, Vanderbilt University School of Medicine, \\ Vanderbilt University Medical Center, Nashville, TN, USA \\ ${ }^{6}$ Department of Pediatrics, Murtala Mohammed Specialist Hospital, Kano, Nigeria \\ ${ }^{7}$ Department of Hematology and Blood Transfusion, Barau Dikko Teaching Hospital Kaduna State \\ University, Kaduna, Nigeria \\ ${ }^{8}$ Department of Pediatrics, University of Arkansas for Medical Sciences/Arkansas Children's \\ Hospital, Little Rock, AR, USA \\ ${ }^{9}$ Developmental Neurosciences, UCL Institute of Child Health, London, UK \\ ${ }^{10}$ Vanderbilt University School of Medicine, Department of Biostatistics, Nashville, TN, USA \\ ${ }^{11}$ Department of Pediatrics, Nashville, TN, USA \\ ${ }^{12}$ Medicine (Hematology/Oncology), Nashville, TN, USA
}

Correspondence and reprint requests to: Michael R. DeBaun, MD, MPH, Vanderbilt-Meharry Center of Excellence in Sickle Cell Disease, Department of Pediatrics, Vanderbilt University School of Medicine, 2200 Children's Way, Room 11206 DOT, Nashville, TN 37232-9000, Phone: 615-875-3040, Fax: 615-875-3055, m.debaun@ vanderbilt.edu.

All authors contributed equally to first authorship.

AUTHORSHIP CONTRIBUTIONS

MRD, MHA, LCJ, NAG, conceived the trial. NAG, SUA, SAA, AMT, ASS, RB, AAG, BC, acquired the data and supervised data collection. SP analyzed the data. MRD, NAG, SUA, LDV drafted the manuscript. All authors were responsible for the full content of the manuscript, analysis and interpretation of data, and critical revision of the manuscript for important intellectual content. All authors had full access to the data and have no competing interests to report. MRD takes responsibility for the paper as a whole. DISCLOSURE OF CONFLICTS OF INTEREST

No conflicts of interest to declare. 
${ }^{13}$ Health Policy (Vanderbilt Institute for Global Health), Nashville, TN, USA

\section{Abstract}

The vast majority of children with sickle cell anemia (SCA) live in Africa, where evidence-based guidelines for primary stroke prevention are lacking. In Kano, Nigeria, we conducted a feasibility trial to determine the acceptability of hydroxyurea therapy for primary stroke prevention in children with abnormal transcranial Doppler (TCD) measurements. Children with SCA and abnormal non-imaging TCD measurements ( $\geq 200 \mathrm{~cm} / \mathrm{s}$ ) received moderate fixed-dose hydroxyurea therapy ( $20 \mathrm{mg} / \mathrm{kg} /$ day $)$. A comparison group of children with TCD measurements $<200 \mathrm{~cm} / \mathrm{s}$ was followed prospectively. Approximately 90\% (337 of 375) of families agreed to be screened, while $92 \%$ ( 25 of 27) of those with abnormal TCD measurements, on two separate occasions, enrolled in the trial. No participant elected to withdraw from the trial. The average mean corpuscular volume increased from $85 \mathrm{fL}$ at baseline to $101.3 \mathrm{fL}$ at 24 months, demonstrating adherence to hydroxyurea. The comparison group consisted of 210 children, of which four developed abnormal TCD measurements, and were started on hydroxyurea. None of the monthly research visits were missed ( $n=$ total 603 visits). Two and ten deaths occurred in the treatment and comparison groups, with mortality rates of 2.69 and 1.81 per 100 patient-years, respectively ( $p=0.67$ ). Our results provide strong evidence, for high family recruitment, retention, and adherence rates, to undertake the first randomized controlled trial with hydroxyurea therapy for primary stroke prevention in children with SCA living in Africa.

\section{Keywords}

Sickle cell anemia; hydroxyurea; acceptability; safety

\section{INTRODUCTION}

One of the most feared and devastating complications for children with sickle cell anemia (SCA) and their family is a stroke. In children with SCA, strokes are now mostly preventable. Abnormal transcranial Doppler (TCD) ultrasound screening coupled with regular blood transfusion therapy has resulted in a significant drop in the rate of strokes.[1, 2] In one tertiary care center in the United States, the stroke incidence rate dropped by approximately 10 -fold (from 0.67 to 0.06 strokes per 100 patient-years) after initiation of TCD screening, with regular blood transfusion therapy for those with abnormal TCD measurements.[2]

Unfortunately, in Africa, no systematic approach has been undertaken to prevent strokes in children with SCA. Nigeria is the country with the largest population of SCA in the world (approximately 150,000 births of children with SCA per year),[3] compared to the United States (approximately 1,700 children with SCA born each year). $[4,5]$ Major obstacles for primary stroke prevention in Nigeria include, but are not limited to: the lack of access to TCD equipment and inadequate training of staff in detecting abnormal TCD measurements. Possibly the greatest challenge to primary stroke prevention in Africa is the inability to replicate the standard of care for primary stroke prevention present in high-income countries, specifically regular blood transfusion therapy for at least a year.[6] Regular blood 
transfusion therapy for stroke prevention is not accepted as an option for most parents of children with SCA because of concerns about cost, safety of blood transfusion and limited blood supply.[7]

Given that regular blood transfusion therapy is not a viable option for primary stroke prevention for children living in Africa, we conducted a single-arm feasibility trial to determine the acceptability of moderate fixed-dose hydroxyurea $(\sim 20 \mathrm{mg} / \mathrm{kg} / \mathrm{day})$ for primary stroke prevention in Nigerian children with SCA (NCT01801423; grant number 1R21NS080639). We tested the primary hypothesis that moderate fixed-dose hydroxyurea therapy is a feasible intervention for children with SCA and TCD measurements $2200 \mathrm{~cm} / \mathrm{s}$. We also established strategies for hydroxyurea toxicity monitoring in Africa and creating stroke prevention teams in Nigeria beyond the setting of the clinical trial.

\section{METHODS}

\section{Study Design}

Ethical approval for the study was obtained from the Institutional Review Boards (IRBs) of Aminu Kano Teaching Hospital (AKTH) and Vanderbilt University Medical Center. Regulatory approval was provided by the National Agency for Food and Drug Administration and Control (NAFDAC) in Nigeria. Written informed consent and assent were obtained prior to screening. The single-arm and single-site feasibility trial was opened for enrollment in April 2013, approximately 6 months after receipt of funding. Enrollment was completed in October 2014. The trial was conducted at the pediatric sickle cell disease (SCD) clinic of AKTH located in Kano, Nigeria. From April 2013 to October 2014, we performed screening procedures on all consented children with SCA to determine those eligible for study therapy. The data were locked for analysis in November 2016.

The inclusion criteria for the moderate fixed-dose hydroxyurea therapy included: 1) confirmed diagnosis of $\mathrm{HbSS}$ or $\mathrm{HbSB}^{0}$, referred to as SCA; 2) two independent TCD timeaveraged mean velocity (TAMV) readings of $2200 \mathrm{~cm} / \mathrm{s}$ in the middle cerebral artery (MCA) using the non-imaging technique, based on validated assessments conducted by two study radiologists or a single measurement $>220 \mathrm{~cm} / \mathrm{s} ; 3$ ) age 5 to 12 years (including the peak age of onset of strokes in SCA, approximately 6 years);[8] 4) ability to swallow an empty(similar size to study therapy) pill capsule prior to treatment; and 5) acceptance of hydroxyurea therapy with minimum follow-up of 12 months on the study therapy. All eligible participants for the trial were offered regular blood transfusion therapy for primary stroke prevention.

The exclusion criteria included: 1) prior history of overt stroke, or concern for moderate to severe neurological deficit based on a positive validated "10 questions" screening; $[9,10] 2$ ) other significant organ system dysfunction (any contraindication to hydroxyurea therapy); 3) history of seizures or diagnosis of epilepsy; 4) prior placement on regular blood transfusion or hydroxyurea therapy; 5) significant cytopenias (absolute neutrophil count $<1.5 \times 10^{9} / \mathrm{L}$, platelets $<150 \times 10^{9} / \mathrm{L}$, reticulocytes $<80,000 / \mu \mathrm{l}$ when hemoglobin level is $>9 \mathrm{~g} / \mathrm{dL}$ ). We excluded children less than 5 years of age due to the high mortality rate as well as malarial and bacterial infections seen in this age group in Nigeria.[11-14] 
The comparison group consisted of individuals who signed the informed consent, had TCD measurements $<200 \mathrm{~cm} / \mathrm{s}$ in the MCA, and agreed to be followed prospectively. The comparison group was followed with at least one standard care visit per year with planned quarterly interim telephone calls to assess status.

\section{Certification in TCD ultrasound scans technique and neurology examination}

Initially, two Nigerian radiologists recruited for the trial were trained and certified after demonstrating reproducibility in assessment of velocity in the MCA with an experienced ultrasonographer in the United Kingdom (who has been teaching non-imaging TCD procedure for two decades). The two on-site radiologists on the trial were certified only in assessing velocity in the MCA using a non-imaging TCD machine (Acuson Sequola, Siemens Healthcare GmbH, Germany). For the TCD training, we used volunteers both with and without SCA, including several with prior abnormal TCD values. After completion of training, one of the two trial radiologists was responsible for training and certifying three non-radiology Nigerian physicians (medical officers) to determine TCD measurements in the MCA only. For the trial-certified radiologist (trainer), we determined the intra-observer coefficient of variation by repeating the TCD measurements in the same participant on the right and left MCA in study participants within 3 hours. Spearman's rank correlation (r) was performed on the two measurements made by the trainer on the right and left side. The minimum acceptable correlation for the trainer's two measurements on each side was set as 0.90 , with an expected lower bound correlation between the trainer and trainee of 0.765 (85\% of the trainer's correlation in the same individual performed only hours apart).

The sample size for the TCD training for the trainees, as compared to the trainer, was calculated using Spearman's rank correlation. Sample sizes of 42 and 31 paired measurements between the trainer and each trainee were associated with a power of $90 \%$ and $80 \%$, respectively, based on the correlation between the trainer and trainee exceeding the lower bound of 0.76. Based on these sample size calculations, we aimed for each medical officer (trainee) and the trainer to have at least 40 paired TCD evaluations. All research physicians were trained and certified on the Pediatric NIH Stroke Scale (PedNIHSS), a validated, standardized neurological examination that was used for the study.[15] Each TCD-certified medical officer performed a minimum of 10 neurological examinations in children, which were verified by experienced pediatric neurologists (L. Jordan, F. Kirkham). The SCA Primary Stroke Prevention Team consisted of a pediatrician, ultrasonographer (medical officer) and pediatric nurse. The clinical team was larger but the team interacted with the children and family daily.

\section{Measurements of feasibility of hydroxyurea therapy required for a phase III trial}

Feasibility of the trial was measured with three outcomes: recruitment, retention, and adherence rates to hydroxyurea therapy. Recruitment rate was measured based on the proportion of participants approached that signed informed consent divided by the number of participants approached. Retention rate was measured based on the proportion of participants that elected to remain in the trial. Adherence rate was measured directly by an increase in mean corpuscular volume (MCV) (with an expected increase of at least 10 femtoliter (fL), and indirectly by the modified Morisky Medication Adherence Scale score 
(MMAS-8).[16-18] The MMAS-8 was previously validated for assessment of hydroxyurea adherence in children with SCA.[16] The MMAS-8 is scored as follow: high adherence (8 points), average adherence ( 6 to 7 points), and poor adherence ( 0 to 5 points).

\section{Sample size for feasibility trial}

After funding of the trial, the AKTH IRB rejected a randomized controlled trial with a treatment and placebo arm of 40 abnormal TCD measurements. Consequently, we elected to enroll 25 participants with abnormal TCD measurements to receive fixed dose hydroxyurea therapy (treatment group) and 210 participants with TCD measurements $<200 \mathrm{~cm} / \mathrm{sec}$ to be followed prospectively (comparison group). The final sample size was based on budgetary restraints.

\section{Safety monitoring and evaluation for participants receiving moderate fixed-dose hydroxyurea therapy}

Monitoring for unanticipated adverse effects was performed two weeks after starting hydroxyurea therapy for all participants; thereafter, monthly. A missed follow-up visit was defined as not being evaluated within two weeks of the scheduled monthly visit. An interval history of medical events and laboratory values was obtained monthly during the planned research visits for each participant. We also interviewed parents during monthly follow-up visits for participants receiving hydroxyurea therapy for assessment of indicators of stroke and adherence. Participants on hydroxyurea therapy were monitored with scheduled research visits monthly for cytopenias. We defined an adverse event as adverse reactions that are expected complications in children with SCD (including pain, acute chest syndrome, priapism, sepsis, splenic sequestration, hospitalization, and blood transfusion). We defined severe adverse events as those leading to prolonged hospitalization beyond seven days, admission into the intensive care unit, near death, or death. We used the Common Toxicity Criteria for Adverse Events.[19]

\section{Safety evaluation for participants in the comparison group}

On an ongoing basis (typically monthly), we reviewed the hospitalization records for individuals in the comparison group and contacted the parents with a goal of at least quarterly to determine if their child was hospitalized, and if so, for what reason. We recorded an annual visit and TCD assessment (as standard care) for participants in the comparison group. When possible, we sought medical records to better characterize the reason for hospitalization and whether the child was still alive (and if not, the cause of death).

\section{Baseline immunization status in participants screened to participate in trial}

Immunization cards, if available, were confirmed for immunization status for Haemophilus influenzae type $\mathrm{b}$ (Hib vaccine) and pneumococcal conjugate vaccine ( $\mathrm{PCV}-13$ vaccine). Otherwise, medical records or parent recall were recorded. Vaccination coverage for Hib and PCV-13 was defined only in cases in which the written record of the immunization matched the oral history. Complete vaccination was defined as three documented doses for Hib vaccination and at least one documented dose of PCV-13. 


\section{Statistical analysis}

We summarized descriptive statistics using median and interquartile range (IQR) for continuous data and percentages for categorical data. The comparison of baseline characteristics between the study and comparison groups was performed using Wilcoxon rank sum test for continuous variables and Pearson's Chi-Square test for categorical variables. Paired Wilcoxon rank sum tests were performed to examine the change in laboratory values from baseline to 3 months and from baseline to 12 and 24 months. All tests used a 2 -tailed probability, with p-values $<0.05$ considered statistically significant. All analyses were performed using $\mathrm{R}$ version 3.1.2.

\section{RESULTS}

\section{Demographics of treatment and comparison group}

A total of 25 participants were initially enrolled in the treatment group and received moderate fixed-dose hydroxyurea therapy (range: 16.5 to $23.5 \mathrm{mg} / \mathrm{kg} / \mathrm{day}$, based on the weight of the child and the capsule size). A total of 210 participants were enrolled in the comparison group. The median ages of the study participants and comparison group were 8 and 6.8 years, respectively. No statistically significant differences were observed in age, sex, ethnicity, height, and weight between the study and comparison groups, Table I. The median (IQR) for follow-up for the treatment and comparison group was 2.14 years $(1.75,2.69)$ and 2.11 years $(1.86,2.48)$, respectively.

\section{Good reproducibility in trainer and successful TCD training in non-radiologists}

The trainer, a board certified Nigerian radiologist, demonstrated reasonable ability to reproduce their results with paired examination in the same participant. The trainer's coefficient of variation obtained in 21 participants for the right and left MCA was $7.6 \%$ and $12.0 \%$, respectively, in the same participant and with the second evaluation occurring within 3 hours after the first evaluation.

The correlation coefficient between the trainee and trainer for the right and left MCA was high. In the right MCA, each trainee had a correlation coefficient greater than $0.90(n=40)$. For the left MCA, the correlation coefficient for each pair was greater than 0.83 for all three trainees $(n=40)$.

\section{Enrollment and retention rates were high}

A total of 375 families were approached to be screened for abnormal TCD measurements, of which $90 \%$ (337 of 375) consented for screening, 8\% (27 of 337) had two consecutive abnormal TCD measurements and were eligible for therapy, and a total of 92\% (25 of 27) participated in the trial and received hydroxyurea therapy. A total of 284 parents of children were approached to be in the comparison group, of which $74 \%$ ( 210 of 284) consented to enroll, Figure 1. None of the families of children with abnormal TCD measurements ( $n=$ 27) agreed to regular blood transfusion therapy for primary stroke prevention. As per protocol, all participants in the treatment group were expected to attend monthly research visits for interval history, physical examination, and laboratory surveillance for assessment of hydroxyurea toxicity. None of the scheduled visits were missed ( $n=$ total 603 visits). 
None of the participants in the treatment group withdrew voluntarily from the trial (retention rate $100 \%$ ). One participant was administratively withdrawn from the study due to development of progressive renal failure after enrolling in the trial. During follow-up visits, four participants in the comparison group converted to abnormal TCD velocities at $8,10,15$ and 19 months after enrollment, respectively.

\section{Adherence rates to hydroxyurea therapy and monthly research visits were high}

Both direct laboratory measures and the parents' assessments of adherence were high. An increase in MCV by at least $10 \mathrm{fL}$ was observed in 22 of the 25 participants, with the mean MCV increasing from $85 \mathrm{fL}$ at baseline to $96 \mathrm{fL}, 98 \mathrm{fL}$, and $101 \mathrm{fL}$ at 3, 12, and 24 months, respectively. In three participants without an increase of at least $10 \mathrm{fL}$ in the MCV values; one participant had an increase in their baseline hemoglobin of $1.9 \mathrm{~g} / \mathrm{dl}, 12$ months after the start of hydroxyrea, and the other two had baseline MCV measurements of $97 \mathrm{fL}$. There was an increase in the mean hemoglobin $\mathrm{F}(\mathrm{HbF})$ level from $8.3 \%$ at month 1 to $11.6 \%, 13.6 \%$, and $14.3 \%$ at 3,12 , and 24 months, respectively. Parental report of adherence based on the modified MMAS- 8 was high, with $100 \%$ of participants demonstrating average to high adherence to hydroxyurea therapy with scores $>6$ points. The mean Morisky score for the feasibility trial was 6.88 , with $10^{\text {th }}$ percentile of $6.62,50^{\text {th }}$ percentile of 7 , and $80^{\text {th }}$ percentile of 7.06. The mean MMAS-8 for each child ranged from 6.0 to 7.12.

\section{Low immunization rates and high chemoprophylaxis coverage among participants}

A low percentage of screened participants had complete, or any, immunization coverage based on for PCV-13 and Hib. Complete coverage for PCV-13 was 13.2\% (43 of 325), with coverage of $12.9 \%, 1.2 \%$, and $0.3 \%$ for the $1^{\text {st }}, 2^{\text {nd }}$, and $3^{\text {rd }}$ doses, respectively. Partial coverage for Hib was $37.5 \%, 35.4 \%$, and $32.6 \%$ for the $1^{\text {st }}, 2^{\text {nd }}$, and $3^{\text {rd }}$ doses, respectively. Complete coverage for Hib was 32.3\% (105 of 325). A total of 8.0\% (26 of 325) of those screened had not received any routine immunizations.

In contrast, a majority of participants had received chemoprophylaxis including anti-malarial medications and penicillin $\mathrm{V}$. The coverage for anti-malarial prophylaxis with daily oral proguanil was $99.1 \%$ (321 of 325), and pneumococcal prophylaxis with daily oral penicillin $\mathrm{V}$ was $78.5 \%$ (255 of 325$)$.

\section{Early results indicate that moderate fixed-dose hydroxyurea therapy is safe}

Serious adverse events and adverse events occurred with similar rates in both the treatment and comparison group, Table II. A total of 12 deaths occurred: 2 deaths in the treatment group (2.69 per 100 patient-years based on intention-to-treat analysis) and 10 deaths in the comparison group ( 1.81 per 100 patient-years) $(\mathrm{p}=0.67)$. The first participant in the treatment group that died was on hydroxyurea therapy for 18 months with a dose of 23.5 $\mathrm{mg} / \mathrm{kg} / \mathrm{day}$. He was hospitalized for infection with severe anemia, subsequently developed seizures, and was treated with broad-spectrum antibiotics, antimalarial therapy, and exchange transfusion. The second participant, initially in the treatment group, developed progressive renal disease of unknown etiology with an initial creatinine of $112 \mu \mathrm{mol} / \mathrm{L}$. The creatinine level gradually increased to $>200 \mu \mathrm{mol} / \mathrm{L}$ until visit 17 , when he was withdrawn from the study, and hydroxyurea was continued on compassionate basis to decrease the 
likelihood of acute vaso-occlusive events. The second participant died one month after being administratively withdrawn from the trial. Of the participants who died, none received PCV-13 vaccinations and only two were vaccinated against Hib. At the time of death, all participants were prescribed malarial prophylaxis, and 10 of 12 participants were prescribed penicillin prophylaxis, Table III. One stroke occurred in a participant in the comparison group, with TCD measurement of $183 \mathrm{~cm} / \mathrm{s}$ in the right MCA and $116 \mathrm{~cm} / \mathrm{s}$ in the left MCA ten months prior to the stroke.

Overall, no laboratory evidence of severe myelosuppression was recorded in any of the participants during the monthly laboratory assessments. Out of 712 complete blood cell counts, the number of times when platelet count $<80 \times 10^{9} / \mathrm{L}$ and absolute neutrophil count $<1.0 \times 10^{9} / \mathrm{L}$ was two and four, respectively; and neither of the values were persistently low after a repeat evaluation with no dose adjustment. Approximately 4.6\% (33 of 712) of all hemoglobin measurements were $<6 \mathrm{~g} / \mathrm{dL}$. Only two children had at least two consecutive hemoglobin levels of $<6 \mathrm{~g} / \mathrm{dL}$ : one with progressive renal failure and ultimately died because of renal failure and the second child with chronic hypersplenism.

\section{DISCUSSION}

Strokes in children with SCA result in immeasurable suffering, disability, and premature death.[20] Despite the majority of children with SCA being born in Africa [3, 4] and the evidence that interventions are available to help prevent strokes, $[6,21]$ no systematic attempt has been undertaken to prevent strokes in this continent. To address this large gap in medical knowledge and humanitarian need, we designed and implemented the SPIN (Stroke Prevention in Nigeria) trial.

Completion of the SPIN Trial had three important findings. First, our results demonstrated that parents of children with SCA in Nigeria have at least similar, if not higher, rates of successful recruitment, retention, and adherence to study medication when compared to comparable trials in high-income countries.[22-24] Second, we provided evidence that creating SCA Stroke Prevention Teams, consisting of a skilled TCD sonographer, pediatrician, and nurse, is feasible in Africa. Third, we demonstrated that for children with SCA living in Africa, in the absence of a completed randomized controlled clinical trial (RCT) for primary stroke prevention, moderate fixed-dose hydroxyurea therapy ( $20 \mathrm{mg} / \mathrm{kg}$ / day) is a reasonable strategy to undertake with monthly clinical and laboratory surveillance.

In Africa, shortages of TCD machines and health care providers with the requisite skills to perform TCD testing (such as radiologists) are major barriers to implementing routine TCD examinations. Obtaining accurate TCD measurements with certified ultrasonographers, who were not radiologist, was the rate-limiting step for our trial. To our knowledge, this is the first effort to establish a TCD training program in non-radiology physicians in Africa. Local practices at our study sites in Nigeria, prevented non-physicians from learning TCD techniques. Our TCD training approach was successful with the inter-observer variability coefficient $>0.8$ among all trainees. Ultimately, when primary stroke prevention becomes a priority in Africa, radiologists will be needed to certify the number of non-physician ultrasonographers. 
Previous studies demonstrated intra- and inter-observer variability were important sources of measurement error in TCD assessments.[25, 26] In addition to observer variability, poorly defined participant TCD variability (or intra-participant standard deviation) must be considered when interpreting TCD measurements. In children with SCA with two TCD measurements evaluated less than 6 months apart, the $95 \%$ confidence limit for change in steady state TCD measurement was $29 \mathrm{~cm} / \mathrm{s}$. [27] In the recently completed TCD with Transfusion Changing to Hydroxyurea (TWITCH) trial, for children receiving blood transfusion therapy with at least 6 measurements, the average within participant variation was between 10.2-12.3 cm/s.[28] To minimize the contribution of participant TCD variability in assessment of intra-observer variability of the skilled radiologist (trainer), we elected for the trainer to repeat the TCD measurement in the same participant within a 3hour time window. The results demonstrated that even in the best of circumstances, there will be a $7-12 \%$ variability in the assessment of TCD when performed by a skilled radiologist in the same child on the same day. Together, these data validate our approach of utilizing entry criteria of two independent TCD values $\geq 200 \mathrm{~cm} / \mathrm{s}$ or one value $>220 \mathrm{~cm} / \mathrm{s}$, preferably performed by a second certified ultrasonographer.

Prior to starting the trial, we were uncertain of the appropriate hydroxyurea treatment dose (fixed-dose $\sim 10 \mathrm{mg} / \mathrm{kg}$ (low), fixed-dose $\sim 20 \mathrm{mg} / \mathrm{kg}$ (moderate), or maximum tolerated dose). However, based on the hydroxycarbamide in very young children with sickle-cell anaemia trial (BABY HUG) where participants were randomly allocated to moderate dose hydroxyurea therapy or placebo, [29] a moderate dose of hydroxyurea is not associated with rates of increased cytopenias. The rate of significant cytopenia (absolute neutrophil count < $1.5 \times 10^{9} / \mathrm{L}$, platelets $<150 \times 10^{9} / \mathrm{L}$, reticulocytes $<80,000 / \mu \mathrm{l}$, unless hemoglobin is $>9$ $\mathrm{g} / \mathrm{dL}$ ) is no different than in children not on hydroxyurea.[29] Further, approximately $80 \%$ of the children in the trial dropped their TCD measurements to $<200 \mathrm{~cm} / \mathrm{s}$, approximately three months after starting hydroxyurea therapy.[30, 31] In comparison, among participants in the Optimizing Primary Stroke Prevention in Sickle Cell Anemia (STOP 2) trial, after initiating of blood transfusion therapy, 52\% of the participants had normal TCD measurements after a mean of 4.3 months.[32] These data, coupled with those from the recently completed TWiTCH Trial demonstrating that hydroxyurea therapy was non-inferior to blood transfusion for primary stroke prevention in children with abnormal TCD measurements, after a year of regular blood transfusion therapy,[6] strongly suggest moderate dose hydroxyurea therapy is a reasonable starting point for primary stroke prevention in Africa.

The vaccination rate was lower than anticipated. The inadequate PCV-13 and Hib vaccination coverage is most likely due to the considerable out-of-pocket expenses for those vaccines for families rather than any lack of counseling on the importance of receiving the vaccines. The median annual family income of $\$ 5490$. The out-of-pocket cost for the one PCV-13 vaccination is $\$ 60$ in Kano, Nigeria. Given the increased risk of infection and observed mortality rate in children with SCA, we believe expanding efforts to treat African children with SCA with hydroxyurea therapy should be coupled with efforts to ensure complete vaccination coverage, at least against $S$. pneumoniae and $H$. influenzae.

As anticipated, the feasibility trial has inherent limitations. First, a median follow-up duration of just over two years does not fully address the concerns about retention for the 
phase III trial (planned therapy for a minimum of least three years), long-term toxicity of hydroxyurea, or whether hydroxyurea therapy has a durable impact on preventing strokes in children with abnormal TCD measurements. The third year was planned as a transition year between the initial R21 funding and receipt of funding for a phase III randomized controlled trial. As a result of funding from the National Institute of Neurological Disorders and Stroke (1R01NS094041), we will follow the participants in the current feasibility trial for a mean duration of 6 years. Additionally, with the new funding, the teams will conduct a RCT comparing moderate fixed-dose hydroxyurea therapy $(\sim 20 \mathrm{mg} / \mathrm{kg} / \mathrm{day})$ to low fixed-dose hydroxyurea $(\sim 10 \mathrm{mg} / \mathrm{kg} /$ day) therapy for primary stroke prevention in children with SCA. Second, the initial interval between obtaining the laboratory values and reviewing them in a timely fashion was less than optimal. To address the challenge, we recruited laboratory personnel allocated to the trial. We also instituted weekly reviews between the study site and coordinating center teams that included a local study monitor whose sole responsibility was to review all laboratory values and follow the safety algorithm. Finally, 10 of 12 reported deaths in the combined treatment and comparison groups occurred at home, with no further examinations performed to determine the cause of death-an intrinsic limitation in attributing cause of death in low- and middle-income countries.[33] In addition to these limitations, challenges relevant to adhering to regulatory guidelines, study medication, and evaluations were described in detail elsewhere.[34]

Results of our first ever NIH-funded SCA stroke prevention feasibility trial in Africa indicate that parents of Nigerian children with SCA are willing to participate in a clinical trial and adhere to hydroxyurea therapy to prevent strokes. We have provided preliminary evidence a moderate fixed-dose hydroxyurea therapy ( $\sim 20 \mathrm{mg} / \mathrm{kg} /$ day $)$ is well-tolerated and may have efficacy in preventing strokes in children with SCA. We have established a practical SCA-specific hydroxyurea safety-monitoring algorithm for children with SCA living in Africa. Until the phase III trial is completed in Africa (NCT02560935), we recommend formation of SCA stroke prevention teams consisting of a certified TCD ultrasonographer, pediatrician, and a nurse, for initiating a moderate fixed-dose of hydroxyurea therapy, coupled with monthly laboratory and clinical surveillance.

\section{Acknowledgments}

We are grateful to our research coordinator Bilya Sani, BA, who tirelessly coordinated the trial in Kano, Nigeria. We appreciate Mrs. Khadija Alkali Bulama and Fahad Usman for facilitating administrative and operational tasks required for the successful conduct of this study. Research reported in this publication was supported by the National Institute of Neurological Disorders and Stroke of the National Institutes of Health Grant \# 1R21NS080639-01, Doris Duke Charitable Foundation, Burroughs Wellcome Foundation, Phillips Family Donation, Aaron Ardoin Foundation for Sickle Cell Anemia, New York University School of Medicine Cardiovascular Research Training Institute (CaRT) Grant \# 5D43TW009140-03, and J.C. Peterson, MD, endowed chair funds from Vanderbilt University School of Medicine. The findings and conclusions in this paper are those of the authors and do not necessarily represent the official position of the National Institute of Health.

\section{References}

1. Adams RJ. Lessons from the Stroke Prevention Trial in Sickle Cell Anemia (STOP) study. J Child Neurol. 2000; 15:344-349. [PubMed: 10830201]

2. Enninful-Eghan H, Moore RH, Ichord R, et al. Transcranial Doppler ultrasonography and prophylactic transfusion program is effective in preventing overt stroke in children with sickle cell disease. J Pediatr. 2010; 157:479-484. [PubMed: 20434165] 
3. Anie KA, Egunjobi FE, Akinyanju OO. Psychosocial impact of sickle cell disorder: perspectives from a Nigerian setting. Global Health. 2010; 6:2. [PubMed: 20170540]

4. Piel FB, Hay SI, Gupta S, et al. Global burden of sickle cell anaemia in children under five, 20102050: modelling based on demographics, excess mortality, and interventions. PLoS Med. 2013; 10:e1001484. [PubMed: 23874164]

5. Therrell BL Jr, Lloyd-Puryear MA, Eckman JR, et al. Newborn screening for sickle cell diseases in the United States: A review of data spanning 2 decades. Semin Perinatol. 2015; 39:238-251. [PubMed: 25979783]

6. Ware RE, Davis BR, Schultz WH, et al. Hydroxycarbamide versus chronic transfusion for maintenance of transcranial doppler flow velocities in children with sickle cell anaemia-TCD With Transfusions Changing to Hydroxyurea (TWiTCH): a multicentre, open-label, phase 3, noninferiority trial. Lancet. 2016; 387:661-670. [PubMed: 26670617]

7. Lagunju IA, Brown BJ, Sodeinde OO. Chronic blood transfusion for primary and secondary stroke prevention in Nigerian children with sickle cell disease: a 5-year appraisal. Pediatr Blood Cancer. 2013; 60:1940-1945. [PubMed: 23956197]

8. Ohene-Frempong K, Weiner SJ, Sleeper LA, et al. Cerebrovascular accidents in sickle cell disease: rates and risk factors. Blood. 1998; 91:288-294. [PubMed: 9414296]

9. Mung'ala-Odera V, Meehan R, Njuguna P, et al. Validity and reliability of the 'Ten Questions' questionnaire for detecting moderate to severe neurological impairment in children aged 6-9 years in rural Kenya. Neuroepidemiology. 2004; 23:67-72. [PubMed: 14739570]

10. Mung'ala-Odera V, Newton CR. Identifying children with neurological impairment and disability in resource-poor countries. Child Care Health Dev. 2007; 33:249-256. [PubMed: 17439437]

11. Ambe JP, Mava Y, Chama R, et al. Clinical features of sickle cell anaemia in northern nigerian children. West Afr J Med. 2012; 31:81-85. [PubMed: 23208475]

12. Grosse SD, Odame I, Atrash HK, et al. Sickle cell disease in Africa: a neglected cause of early childhood mortality. Am J Prev Med. 2011; 41:S398-405. [PubMed: 22099364]

13. Ikeh EI, Teclaire NN. Prevalence of malaria parasitaemia and associated factors in febrile under-5 children seen in Primary Health Care Centres in Jos, North Central Nigeria. Niger Postgrad Med J. 2008; 15:65-69. [PubMed: 18575475]

14. Ezeonwu B, Chima O, Oguonu T, et al. Morbidity and mortality pattern of childhood illnesses seen at the children emergency unit of federal medical center, asaba, Nigeria. Ann Med Health Sci Res. 2014; 4:S239-244. [PubMed: 25364596]

15. Beslow LA, Kasner SE, Smith SE, et al. Concurrent validity and reliability of retrospective scoring of the Pediatric National Institutes of Health Stroke Scale. Stroke. 2012; 43:341-345. [PubMed: 22076000]

16. Thornburg CD, Calatroni A, Telen M, et al. Adherence to hydroxyurea therapy in children with sickle cell anemia. J Pediatr. 2010; 156:415-419. [PubMed: 19880135]

17. Oliveira-Filho AD, Barreto-Filho JA, Neves SJ, et al. Association between the 8-item Morisky Medication Adherence Scale (MMAS-8) and blood pressure control. Arq Bras Cardiol. 2012; 99:649-658. [PubMed: 22688844]

18. Krousel-Wood M, Islam T, Webber LS, et al. New medication adherence scale versus pharmacy fill rates in seniors with hypertension. Am J Manag Care. 2009; 15:59-66. [PubMed: 19146365]

19. U.S. Department of Health and Human Services NIoH, National Cancer Institute. Common Terminology Criteria for Adverse Events (CTCAE). 2010

20. Powars D, Wilson B, Imbus C, et al. The natural history of stroke in sickle cell disease. Am J Med. 1978; 65:461-471. [PubMed: 717414]

21. Adams RJ, McKie VC, Hsu L, et al. Prevention of a first stroke by transfusions in children with sickle cell anemia and abnormal results on transcranial Doppler ultrasonography. N Engl J Med. 1998; 339:5-11. [PubMed: 9647873]

22. Walsh KE, Cutrona SL, Kavanagh PL, et al. Medication adherence among pediatric patients with sickle cell disease: a systematic review. Pediatrics. 2014; 134:1175-1183. [PubMed: 25404717]

23. DeBaun MR, Gordon M, McKinstry RC, et al. Controlled trial of transfusions for silent cerebral infarcts in sickle cell anemia. N Engl J Med. 2014; 371:699-710. [PubMed: 25140956] 
24. Adams RJ, Brambilla DJ, Granger S, et al. Stroke and conversion to high risk in children screened with transcranial Doppler ultrasound during the STOP study. Blood. 2004; 103:3689-3694. [PubMed: 14751925]

25. Baumgartner RW, Mathis J, Sturzenegger M, et al. A validation study on the intraobserver reproducibility of transcranial color-coded duplex sonography velocity measurements. Ultrasound Med Biol. 1994; 20:233-237. [PubMed: 7914715]

26. Maeda H, Etani H, Handa N, et al. A validation study on the reproducibility of transcranial Doppler velocimetry. Ultrasound Med Biol. 1990; 16:9-14. [PubMed: 2181766]

27. Brambilla DJ, Miller ST, Adams RJ. Intra-individual variation in blood flow velocities in cerebral arteries of children with sickle cell disease. Pediatr Blood Cancer. 2007; 49:318-322. [PubMed: 17243135]

28. Russell E, Ware Adam Lane, Schultz William H, et al. Variation in Serial TCD Velocity Measurements in the TCD with Transfusions Changing to Hydroxyurea (TWiTCH). Trial. 2016; 128(22): 1019.

29. Wang WC, Ware RE, Miller ST, et al. Hydroxycarbamide in very young children with sickle-cell anaemia: a multicentre, randomised, controlled trial (BABY HUG). Lancet. 2011; 377:1663-1672. [PubMed: 21571150]

30. DeBaun M, Galadanci N, Kassim A, et al. Primary stroke prevention in children with sickle cell anemia in Africa : The false choice between patient oriented research and humanitarian service. Transactions of the American Clinical and Climatological Association. 2016; 171:17-33.

31. Galadanci NA, Abdullahi SU, Tabari MA, et al. Primary stroke prevention in Nigerian children with sickle cell disease (SPIN): Challenges of conducting a feasibility trial. Pediatr Blood Cancer. 2014

32. Kwiatkowski JL, Yim E, Miller S, et al. Effect of transfusion therapy on transcranial Doppler ultrasonography velocities in children with sickle cell disease. Pediatr Blood Cancer. 2011; 56:777-782. [PubMed: 21370410]

33. Ndila C, Bauni E, Nyirongo V, et al. Verbal autopsy as a tool for identifying children dying of sickle cell disease: a validation study conducted in Kilifi district, Kenya. BMC Med. 2014; 12:65. [PubMed: 24755265]

34. Debaun MR, Galadanci NA, Kassim AA, et al. Primary Stroke Prevention in Children with Sickle Cell Anemia Living in Africa: The False Choice between Patient-Oriented Research and Humanitarian Service. Trans Am Clin Climatol Assoc. 2016; 127:17-33. [PubMed: 28066035] 


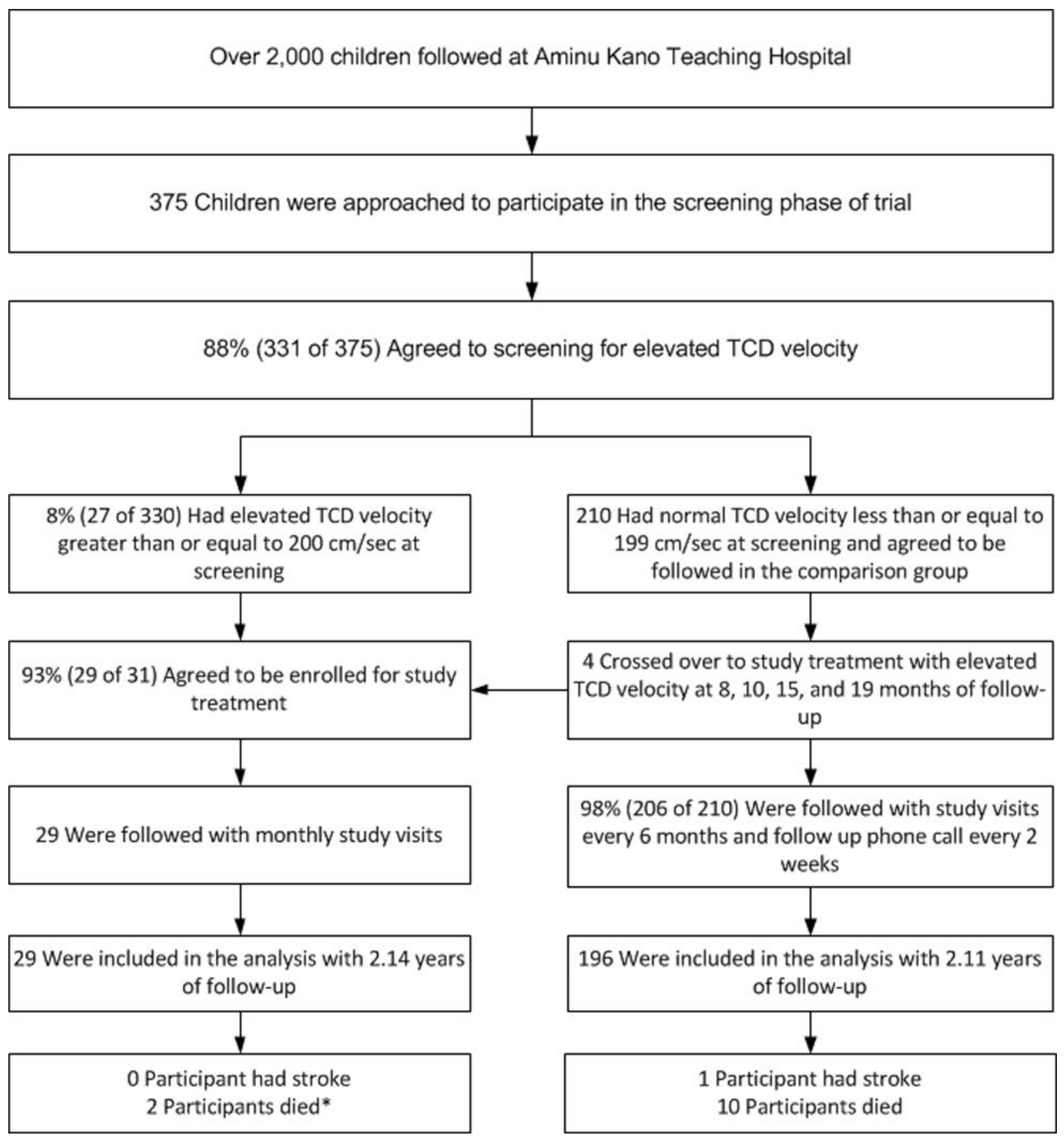

Figure 1.

SPIN Trial Participants Recruitment Flow Diagram 


\section{Table I}

Baseline demographics and characteristics of all children with sickle cell anemia enrolled in in SPIN Trial

\begin{tabular}{|c|c|c|c|}
\hline Demographics: & $\begin{array}{c}\text { Treatment } \\
\mathbf{N}=\mathbf{2 9}^{\mathbf{E}}\end{array}$ & $\begin{array}{l}\text { Comparison } \\
\mathrm{N}=206\end{array}$ & $P$ value \\
\hline Age (years), median (IQR) & $6.8(5.7,9.2)$ & $8.2(6.3,10.4)$ & 0.053 \\
\hline Gender (Female), \% & 52 & 52 & 0.94 \\
\hline Height $(\mathrm{cm})$, median (IQR) & $\begin{array}{c}123.0 \\
(114.0,134.0)\end{array}$ & $125.5(115.2,132)$ & 0.47 \\
\hline Weight (kg), median (IQR) & $20.0(17.0,23.0)$ & $20(17.0,24.0)$ & 0.60 \\
\hline Ethnicity (Hausa/Fulani), \% & 81.5 & 91.8 & 0.17 \\
\hline Tertiary education for parent (college/university training), \% & 48 & 79 & 0.001 \\
\hline Length of follow-up (years), median (IQR) & $2.1(1.8,2.7)$ & $2.1(1.9,2.5)$ & 0.44 \\
\hline \multicolumn{4}{|l|}{ Annual income $e^{ \pm}$} \\
\hline$<\$ 5000$ & $48 \%$ & $36 \%$ & \\
\hline$>=\$ 5000$ & $52 \%$ & $64 \%$ & 024 \\
\hline Mean & 4183 & 5395 & 0.24 \\
\hline Median & 4270 & 6100 & \\
\hline Hydroxyurea dose (mg/kg/day), minimum and maximum dose & $\begin{array}{c}19.23 \\
(16.58,21.88)\end{array}$ & none & \\
\hline
\end{tabular}

${ }^{ \pm}$United States Dollar

Includes crossovers from the comparison group to the therapy group 


\section{Table II}

Comparison of incidence rates of hospitalization in the first 36 months between the treatment and comparison groups in the SPIN trial

\begin{tabular}{|c|c|c|}
\hline Indication for hospitalization & Treatment Group (Per 100 person-years) & Comparison Group (Per 100 person-years) \\
\hline Acute chest syndrome & 0 & 0.54 \\
\hline Osteomyelitis & 0 & 0.54 \\
\hline Infection & 6.73 & 2.18 \\
\hline Pain & 12.12 & 21.22 \\
\hline Stroke & 0 & 0.18 \\
\hline Transfusion & 8.08 & 3.63 \\
\hline Malaria positive WHO* & 9.42 & 12.15 \\
\hline Fever & 12.12 & 7.07 \\
\hline Other & 8.08 & 2.53 \\
\hline Total & 56.54 & $\mathbf{5 0 . 2 4}$ \\
\hline
\end{tabular}

World Health Organization 


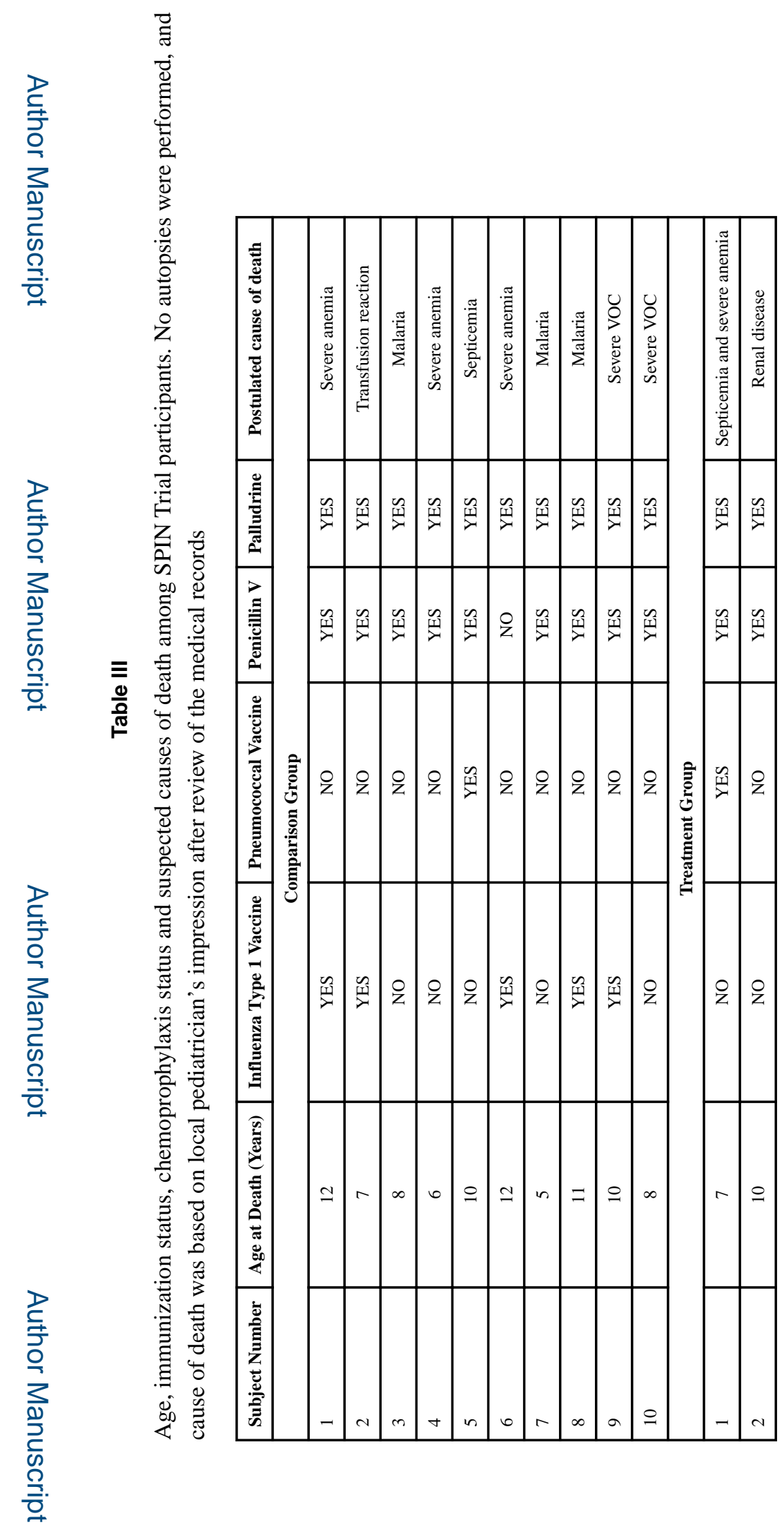

Am J Hematol. Author manuscript; available in PMC 2018 August 01. 